\title{
THE USER-DRIVEN MINIMUM FEASIBLE PRODUCT - TOWARDS A NOVEL APPROACH ON USER INTEGRATION
}

\author{
S. J. Nicklas ${ }^{1, \otimes}$, A. Atzberger ${ }^{1}$, J. C. Briede-Westermeyer ${ }^{2}$ and K. Paetzold ${ }^{1}$ \\ ${ }^{1}$ Bundeswehr University Munich, Germany, ${ }^{2}$ Universidad Técnica Federico Santa María, Chile \\ $\bigotimes$ simon.nicklas@unibw.de
}

\section{Abstract}

User integration is a key aspect of new product development. When applying corresponding methods, however, there is a communication gap that needs to be overcome by the designer. Prototyping is a means to bridge this disjunction, yet brings its own set of hermeneutic limitations. Taking a closer look at the processual information exchange, we propose the concept of the userdriven minimum feasible product (UD-MFP). It describes the artefact generated by the users themselves in their specific context, which contains the essence of the problem's solution as a possible source of validation.

Keywords: prototyping, design theory, design research, user integration, media richness theory

\section{Introduction}

Innovation, the base for business competitiveness, requires tools that allow the continuous development of solutions that have an impact and are sensitive to the context, starting from drawing up the needs, which faithfully represent reality. This is a great challenge, which without a doubt requires being systemically addressed, balancing the benefits both for the company and for the end user, the person who will be interacting with the technical products and/or systems developed on a daily basis. In that sense, although the technological potential is key to correctly developing the product, you also have to focus on explaining what the right product to develop is (Buxton, 2007).

One strategy is to jump the traditional design process and address the early phases of the ideation process, known as Front End of Innovation (FEI) or Fuzzy Front End (FFE) (Heck et al., 2016). From the moment where the strategy of the product is formulated, opportunities are identified and chosen, ideas are generated, assessed and chosen, and the concept is developed and tested (Stevanović et al., 2016). User integration is a key aspect within these early stages of the new product development that is generally addressed through corresponding design methods. However, the designer needs to overcome a communication gap. Prototyping, which is highly encouraged and promoted in methodologies like design thinking (Brown, 2009), bridges this disjunction to ensure that the user understands the aspects of operation and usage of the product, but brings its very own set of hermeneutic limitations.

Current approaches to address the communication gap through prototyping largely rely on the designer's initial understanding of the design challenge at hand. They follow the principle of finality as described by Hansen (1974) and are predominantly viability- and desirability-driven. We want to challenge this habit and propose a different starting point for investigation. Therefore, we take a closer 
look at the processual information exchange and propose the concept of the user-driven minimum feasible product (UD-MFP). It describes the artefact generated by the end-users themselves with their limited set of resources in their specific context - cf. section 4.2. This physical proposal contains the essence of the problem and its solution as a possible source of information on user needs and requirements as well as a means of validation, minimizing the initial iterations of exploration. In the course of this theoretical paper, we will answer the question of what are the differences between classic prototyping and the concept at hand and what are the corresponding implications for the design process.

On the one hand, the question of why the emergence of resource-limited UD-MFP seems to be easier to observe in developing countries finds a proper answer in Gulati's (2010) observation, that "(...) frontier problems tend to encourage ad hoc solutions." Talking about environment-specific boundary conditions and resource scarcity, the concept of frugal innovation comes to mind, that saw increasing interest in the scientific community before the term itself was defined by Bhatti and Ventresca (2013) as follows: "Frugal innovation is a means and ends to do more with less for more people." There are two distinct points of view that Bhatti and Ventresca (ibid.) provided; a historical and a more recent one. Both have a contextual notion with a focus on the macro environment and the economic premises. Resource scarcity is a major driver for frugal innovation, though the developed solutions may as well be useful in developed countries. Another frequently mentioned term in the same context is Jugaad. While Jugaad innovation promotes additional flexibility and non-linearity, seeking nonmainstream customers (Radjou et al., 2012), it still operates from an entrepreneurial or corporate point of view (Cappelli et al., 2010). There are analogies between Jugaad and the concept presented at hand but they focus on different aspects and are far from being identical. Both are easier to observe in developing countries, yet, Jugaad neither explains the creation of prototypes nor the effect filters have on prototyping. On the other hand, added flexibility and the integration of the user became a central theme in product development at the latest with the advent of agile development. The authors argue that the understanding of the communicational filters in place is a crucial prerequisite that can benefit from a thorough examination of the UD-MFP and its differences to the current state of the art. Therefore, we hope that this paper can contribute towards an approach for increased efficacy in user integration.

For easier reading comprehension throughout this paper, we will regularly use the singular terms 'designer' and 'user' irrespective of their factual gender or count.

\section{Research approach}

In the present research, a comprehensive structured literature review has been undertaken. We defined key terms and chose the most-cited publications in prototyping literature for a first investigation. Based on that, we extracted the definitions of the respective terms and put them into perspective regarding the introduction of a new concept called 'user-centred minimum feasible product'. We defined and subsequently explained this concept with the help of a real-world example. Furthermore, we compared this new concept to the previously identified terms, investigated their influence and drew corresponding delimitations. The findings have been analysed and merged into a communicational scheme to display its linkages as well as its distinctions. This scheme represents the foundation of the new concept. Its suitability for the general field of product development has been checked by drawing comparisons to classical prototyping approaches. In order to ensure the validity of the concept, we based this work on a triangulation of similar concepts in literature.

\section{State of the art}

The key factor for user integration in the development process is the ability to pinpoint and validate the user's needs through information exchange. Typically, prototyping and co-design approaches facilitate this dialogue by providing a materialization of the matter under discussion that helps to envision a future usage of a product in its designated context. Prototyping in itself as well as its usage in the context of co-design together with the occurring filters in this type of communication form the basis for the concept of the user-driven minimum feasible product. 


\subsection{Prototyping}

The prototype is a key part of the design process of new products. If we analyse this from the point of view of design engineering, Liou (2007) and Ulrich and Eppinger (2012) identify that its use covers four purposes: Learning, Communication, Integration and Milestones. The prototype allows verifying and validating assumptions, calculations and decisions during the development, as well as answering two key questions: "Will it work?" and "To what extent does it satisfy the customer's needs?" (ibid.). Lauff et al. (2018), answering the question of what a prototype is and investigating its role within companies, set out an updated definition: "A prototype is a physical or digital embodiment of critical elements of the intended design, and an iterative tool to enhance communication, enable learning, and inform decisionmaking at any point in the design process" (page 10), not restricting the corporeality and materiality ${ }^{1}$, focusing on the critical elements of the design's intention. As an iterative tool prototyping allows supporting communication between the team and stakeholders, continuous learning, and as a tangible means to inform the decision-making process. According to Camburn et al. (2017), the creation of prototypes often predetermines a great part of the deployment of resources in the development and affects the success of the design project. They identify three goals for the design of a prototype: Refinement, Communication and active learning and how and when to include this within the design process (page 33): tests, synchronization, ideation, setting, feedback, usability, fidelity. Due to the trend of integrating Design Thinking into product development and business areas, prototyping in early stages has become an important activity (Elverum et al., 2016), allowing idea validation and testing processes to be sped up. The core aspect of the agile approach within the physical development of the product is the creation of prototypes (Zink et al., 2017). Unlike plan-based development, the prototypes are used to explore, design, check, and test the usability or communicate aspects of the product. The creation of prototypes ahead of time is different from the creation of traditional prototypes and changes the purpose of the creation of prototypes from the validation to the experimentation (Punkka, 2012).

Through daily use in academia, industry and media, the term "prototype" gathered several connotations that might differ from the aforementioned definition. In order to cope with the resulting taxonomic fuzziness, several neologisms were introduced to reframe the meaning:

A Provotype is a provocative prototype (Boer and Donovan, 2012), introduced in the design development process to provoke a reaction: provoking and involving people so that they imagine possible futures. The emphasis of this tool is not in defining a problem (overcoming unpleasant situations), but rather in exploring opportunities (making possibilities possible). This allows, on the one hand, to provide companies and participants of the ethnographic studies with techniques to explore a gamut of possibilities and, on the other hand, to provoke them to experience the phenomena associated to a situation in a different way (Boer, 2011). Pretotypes allow testing the initial attraction and the real use of a potential new product, simulating its core experience with the least investment possible in terms of time and money (Savoia, 2011). Minimum Viable Products (MVP) are an advanced strategy where a new product or service is created with enough characteristics to satisfy the first customer. These early adopters are anxious to try something new and will give their opinion (Ries, 2011). This arises as a means to face the "conditions of extreme uncertainty" (p.8), which start-ups face (ibid.), for whom developing a complete product before testing a concept in the market, is a risky option. It allows a start-up to learn from experiments, which test a version of a product against relevant metrics (Moogk, 2012). Duc and Abrahamsson (2016) explore and identify the following applications of MVPs: supporting validated learning, facilitate product design, bridging communication gaps, and facilitating cost-effective product development activities. To sum up, the focus of the MVP lies in testing the market relevance of a product proposal. Pirtype: In contrast to traditional prototypes Schmidt (2019) introduces the term "pirtype". Pirtypes emphasize the experimental character of development and loosen the focus on the physicality of the artefact. They rather "[...] aim at extending the knowledge base" (ibid.). Compared to releases, however, pirtypes (and prototypes as well) do not need to be productive. Instead, the intention is to test a product increment with its destined user base. Accordingly "[t]hey embody the current knowledge base in order to validate it. [...] Thus, pirtyping denotes pushing the concept towards the intended goal by encouraging the team to try new directions and emphasize learning while also allowing non-physical artefacts." (ibid.)

\footnotetext{
1 “A prototype is any representation of a design idea, regardless of the means." (Houde and Hill, 1997)
} 
Aforementioned definitions show that there are several distinctions but also similarities between the terms. We agree with the distinctive indication of Houde and Hill (1997) and Schmidt (2019) that a prototype is not bound to specific means, especially that its physicality is not a required premise. While there is an overlap between the initial meaning of prototyping and the definition of pirtyping and we, therefore, do not agree that a clear line between these terms can be drawn, we support 'pirtyping' as a means of distinction that emphasizes the usage as a tool for validation through information exchange. Therefore, when we use the terms 'prototype' and 'prototyping' in the following text, we refer to the usage in the sense of 'pirtype' and 'pirtyping', which can be physical, digital or even virtual.

\subsection{Co-design}

Co-design, according to Sanders and Stappers (2008), understood as a specific moment of co-creation, is collective creativity between designers and collaborators; people not trained in design who work together in the development process of the design. In contrast with the passive role of the user in classic user-centred approaches, in the co-design process, the users can take part in the development process as "experts of their experiences" (Visser et al., 2005), depending on their level of experience, passion and creativity, and become 'designers', while the professional designer acts as the main facilitator, guide or support (Sanders and Stappers, 2008).

In this setting that the collaboration seeks, it is essential to be supported by different media to have effective communication and not just with regard to fulfilling the project's goals, but to be able to open spaces of consensus. The designer and user, in this mediation process, are externalizing ideas and notions about the topics addressed, using media that helps make these tangible, where using drawings, sketches, even models and prototypes, can help significantly to create a shared understanding (Møller and Tollestrup, 2013), not only of the solution device created but of the diagnosis of a problem/opportunity, of the design task, the requirements, the restrictions and the boundary conditions.

The prototypes have to be understood as 'devices', holistic precursors of the end product (Sanders and Stappers, 2014) and as means or routes to discover other things: "Things we do to discover things" (Stappers, 2013, p. 86). The generative probes and tool kits are two approaches highlighted in the practice of co-design (Sanders and Stappers, 2014). The probes invite people to reflect and express their experiences, feelings and attitudes. Their goal is to obtain inspiring responses from the people, prioritizing the fragmented clues about their lives and thoughts more than exhaustive information (Gaver et al., 2004), in forms and formats that can inspire the designers (Gaver et al., 1999). According to Sanders (as cited in Sanders and Stappers, 2014) the generative tool kits meanwhile describe "a participatory design language that can be used by nondesigners (i.e. future users) in the front end of design so that they can imagine and express their own ideas about how they want to live, work and play in the future".

In co-design, the generation of prototypes is essential in the later stages of the design process, once a design opportunity has been identified and its possible roles understood (Stappers, 2013):

(1) Prototypes evoke a focused discussion in a team because the phenomenon is 'on the table', (2) allow testing a hypothesis, (3) confront theories, because instantiating one typically forces those involved to consider several overlapping perspectives/theories/frames, (4) confront the world because the theory is not hidden in abstraction, (5) and can change the world because in interventions it allows people to experience a situation that did not exist before.

\subsection{Filters in communication}

A key challenge originating in the use of these artefacts for means of validation is the question of how to convey the necessary information during testing. Based on Daft and Lengel's (1983) concept of Media Richness in organizational communication, Schmidt et al. (2017) extended this theory to the realm of object-based communication media, i.e. prototypes, and thus provide an explanatory model for the informational exchange. Schmidt et al. (ibid.) argue that "there is a fit between communication and prototype." Therefore, the media richness of a prototype has to be just right for the communication task at hand. A close-to-final-product can be too elaborate and distract from the core purpose, while a simple drawing might not convey enough information to the evaluator to start with. Schmidt (2019) identifies three dimensions of a prototype's information: fidelity, resolution and scope. This means a prototype has to contain the right information as well as the right amount of information in regards to the question that 
is to be inspected. Figure 1 shows the flow of information during the test of prototypes as well as the corresponding filters of understanding. Schmidt et al. (2017) promote the question of which prototype to build as a key factor of development by the means of prototypes. Similar to the filters in Schmidt's modified Media Richness Theory (MRT), Lim et al. (2008) analysed the structure of prototypes and identified five dimensions of prototypes that act as filters: appearance, data, functionality, interactivity, and spatial structure. Thus, we can conclude that a prototype acts as a filter in communication since its designer purposefully crafted its anatomy beforehand to represent a chosen set of information.

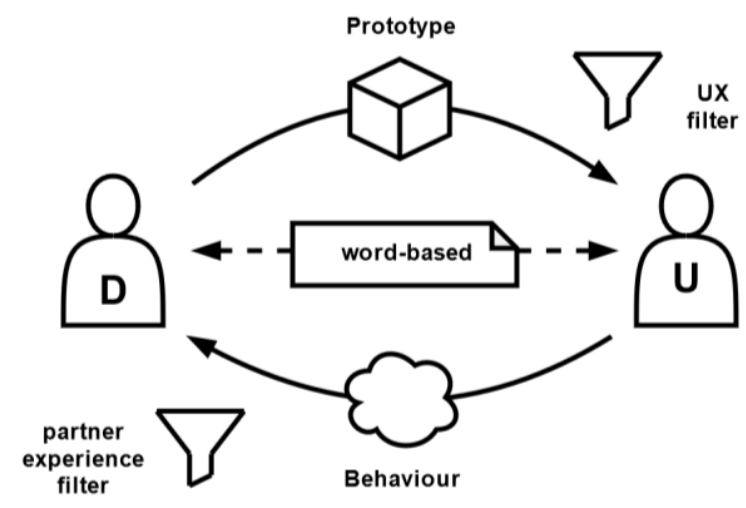

Figure 1. Communication between designer and user using prototypes (Schmidt et al., 2017)

Another filter in the loop originates from the differences in knowledge, experience and social background between the designer and the user. In the way Schmidt et al. (2017) transferred the MRT to the realm of prototyping, Ricour (1972) already expanded the concept of hermeneutic interpretation to every objectivationable human action. In this sense, as soon as the prototype is handed over to the user, the recipient then interprets the contained information. This interpretation only happens where the hermeneutic horizons of the designer and the user share common ground. Again, the information that is not covered by this overlap is therefore filtered or misunderstood in return.

\section{Findings}

Based on the previously outlined topics, we derive the concept of the user-driven minimum feasible product. Thus, we take a closer look at the processual information exchange in 'classical' prototyping, co-design and the UD-MFP setting respectively. For that, we demonstrate the similarities as well as the unique distinctions of the concepts at hand and show how they develop from one to another.

\subsection{The user-driven minimum feasible product (UD-MFP)}

In order to take a closer look at the concept at hand, we will introduce the term 'user-driven minimal feasible product' (UD-MFP), that describes the artefacts created by end-users with their limited set of resources (e.g. money, tools, materials, knowledge) to satisfy urgent needs, when appropriate solutions are either not available or out of reach. By definition, the user initiates the creation of the UD-MFP (see Figure 2) and it, therefore, focuses implicitly on needs that are urgent enough to provoke the user to build an ad hoc solution.

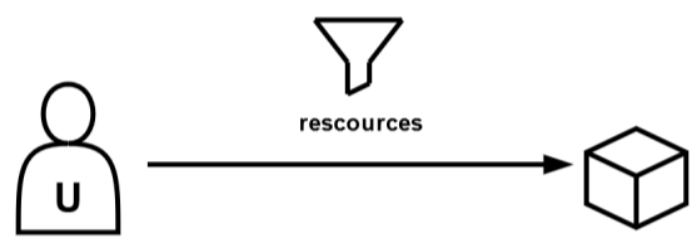

Figure 2. The initial UD-MFP setup

Through this focus, the user creates a non-verbalised hierarchy of his needs, displaying his most important, solvable problem. In contrast to viability- or desirability-driven approaches, the adjective 
'feasible' promotes the notion of building a one-off working product, since the single user does not need to consider market acceptance or business viability and has no intention to sell the product to a third person. Then again, the desirability of the UD-MFP is an intrinsically given treat, usually but not necessarily limited to the single user and the corresponding use-case.

\subsection{UD-MFP example case}

To exemplify the UD-MFP, we are located in the street context of street vendors in Valparaíso, Chile. These users, who, in very precarious conditions, generate informal urban appropriations (Ojeda and Pino, 2019), resort to this UD-MFP strategy almost spontaneously, with a pragmatic orientation, configure immediate solutions with available resources. This street vendor, who is 75 years old and is depicted in Figure 3, sells candy and chocolates to students outside the University. For which he uses a series of adapted and other reused elements to solve at least three major needs or requirements that we identified: (1) Transfer (merchandise and stall), (2) show and exhibit merchandise (sweet chocolates), (3) sit down and attend his stall. Going into detail, we can derive a series of design criteria: A larger box has a double function; to transfer the merchandise and to serve as a basis for the product display surface (1.1). The structure of the car extends with two pieces of wood to form a support to carry the boxes (1.2). Finally, this cart is symbolically tied with a wire to the tree as a way of appropriating the place (1.3). The tablecloths give homogeneity to the display surface. The jar serves to store things and serves as a floor to sit on (3.1).
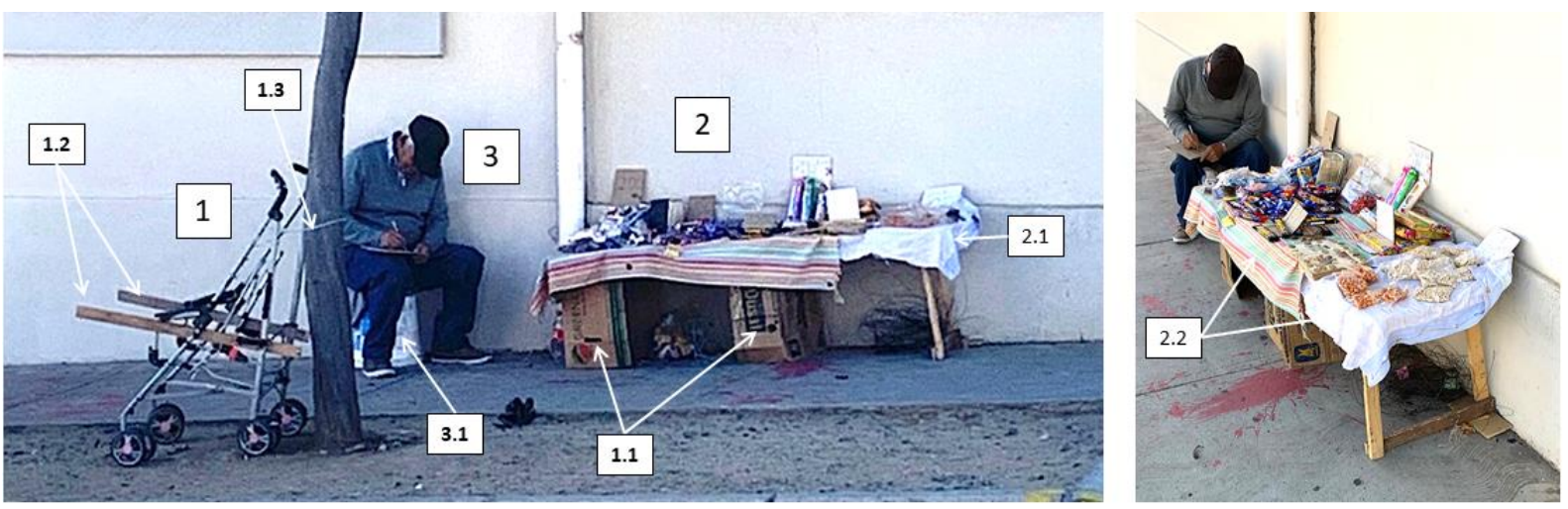

Figure 3. The street vendor

From this scene, we can (a) observe and understand the user's interaction with the MFP in his very own context of use, (b) understand the purposes, needs and minimum requirements that the product (in its entirety and interaction between its parts) must meet and (c) recognize it as a very valuable milestone, which represents and evidences the attributes and "the essence of the product" that can be understood as a germ or seed to start the development of a new product.

\subsection{Implications}

As shown in section 3.3, every communication task between the designer and the user is filtered. This is especially true for the process of prototyping. Depending on how the user is integrated into the process, the location and type - and therefore the impact - of the filters vary as shown below (Figure 4). Starting from the 'classic' approach described by Schmidt et al. (2017), we derive an analogous scheme for codesign and finally shift towards the UD-MFP. In the 'classical' prototyping approach, the designer develops a prototype. This artefact is based on his assumptions about the user's needs, his own experiences and his knowledge - and therefore limited by his hermeneutic horizon. Additionally, this prototype may be an incomplete representation of the designer's idea and only contain selective information according to the media richness theory - Schmidt et al. (ibid.) summarize this under the term user experience filter. The situation in which the user is handed over the prototype, along with the set-up of the testing environment, can have further influence on the user's thought and communication process - compare the systemic view of communication by Eckert et al. (2005, pp. 237-238). This means the informational content of the artefact is already highly filtered, modified and 
pre-determined when the user interacts with the prototype. This interaction is in turn observed by the designer and re-transformed into usable information for the design process. The outcome of the transformation is depending on the designer's experience, also known as partner experience filter (Schmidt et al., 2017), and the hermeneutic gap between the designer and the user's actions. Besides this object- and behaviour-based communication, there is a verbal information exchange to support the process: while the designer can verbally assist with the understanding of the prototype, the user expresses his thoughts and gives feedback. At the same time, the guiding of the designer can lead to an experimental bias in form of the Rosenthal effect (Rosenthal and Fode, 1963) or Hawthorne effect (Duraiswamy et al., 2018).

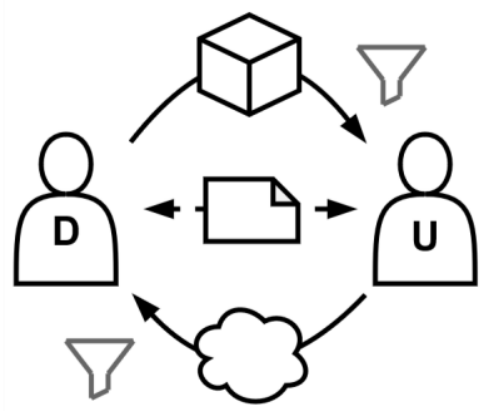

'classic' prototyping

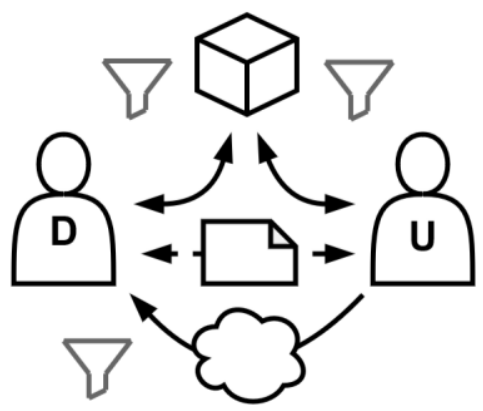

co-design

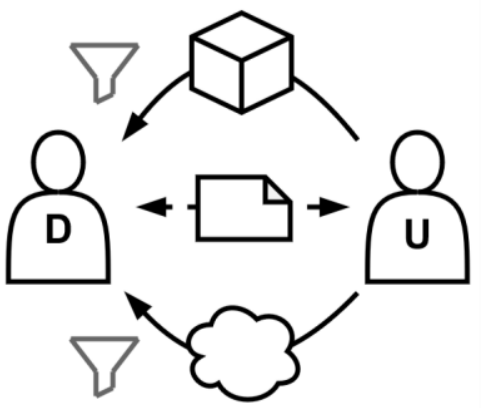

UD-MFP 2021

Figure 4. Filters in different constellations between designer and user - derived from Schmidt et al. (2017)

In the case of a co-design set-up for prototyping, the position and type of the filters shift. Now, the prototype is created in a joint effort. While the hermeneutic gap for the created artefact diminishes, the verbal and situational influences on the user increase. As a result, the user's understanding for the prototype expands. Yet, its creation relies on a common understanding of the problem-space between designer and user. In theory, this improves the designer's comprehension of the design task but bears the risk that the designer's bias affects the outcome in a way that the prototype does not properly reflect the user's initial needs. On the upside, the number of modalities for the information flow in the direction of the designer increases and includes the object-based information of the prototype.

Looking at the creation process of the UD-MFP, however, it becomes clear, that there are no interrupting informational filters in place between the user and the emerging artefact. The only - but nonetheless important - constraints are the user's resources and the hermeneutical distance that originates from the manifestation of the initial idea. Furthermore, the user is free from any influence by $\mathrm{a}$ - in this case still hypothetical - professional designer. The artefact, therefore, represents an original problem-solver. The meaning of the artefact is two-fold. From the user's perspective, it classifies as a 'product'; it is intended to be used in a real-world situation in order to support the daily routine. From the designer's view, however, there is a 'prototype' that needs interpretation; a first manifestation of a problem solution with potential for improvement in later iterations.

The question at hand is how to integrate the designer into this construct. There are three touch points as depicted in Figure 4. First, there is the artefact itself as a means of an informational resource. In contrast to the classical approach or the co-design variant, the flow of information is reversed. Second, the designer can observe the user's interaction with the UD-MFP. In itself this equals the informational flow in the classic environment - the difference lies in the shifted origin of the artefact as the basis for the interaction. In contrast to the 'classical' prototype that emanates from the designer's hermeneutic horizon or, in case of co-design, from a common ground of understanding, the UD-MFP arises solely from the user's point of view as shown in Figure 5. Therefore, to understand the UD-MFP the designer needs to extend his horizon to facilitate the fusion of horizons. On the one hand this might look like an imbalance, because the responsibility and the workload for the transformational process is mainly on the designer's side, which increases the difficulty of the designer's task, on the other hand, the designer as a professional can cope with it through experience 
and continuous learning, narrowing down the error - cf. Donald Schön's "reflective practitioner" (Jahnke, 2012). At the same time, the untrained user can stay in his 'comfort zone'. The third connection is the verbal one. Instead of guiding the user, the designer needs to extract the user's motivation, reasoning and context in order to complement his understanding.

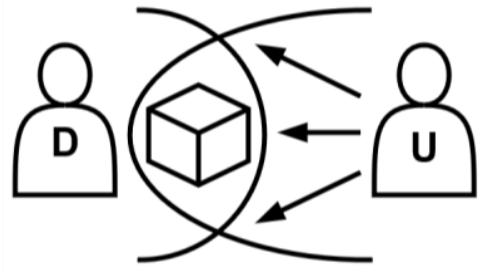

'classic' prototyping

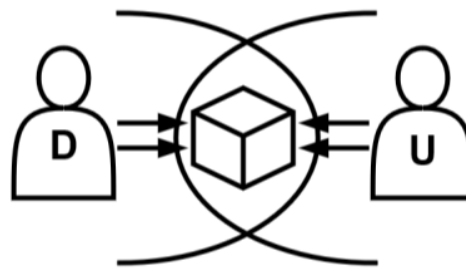

co-design

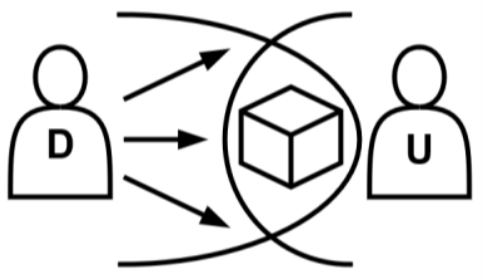

UD-MFP 2021

Figure 5. Facilitating the fusion of horizons

To summarize, the filtering characteristics and their implications on the design process change substantially from the classical set-up to the UD-MFP-driven approach. This requires an adjustment in the interpretation habit and the consideration of different 'translation' processes of the designer. However, the user - as a layman - is burdened with less intellectual and transformational workload.

\section{Conclusion and outlook}

\subsection{Why a new term is necessary}

The concept of the user-driven minimal feasible product touches different topics and shares several similarities with them. First, there is the field of prototyping. As pointed out in section 3.1, there is ambiguity in regards to the meaning of the terms 'prototype' and 'prototyping' and their connotations. Nevertheless, it mainly focuses on the development-driven creation of prototypes and their testing in the loop. Our proposed concept, however, emphasizes the reverse process; based on the causation principle with the user as the starting point. Second, the UD-MFP continues the integration of the user from the co-design approach and transfers the process ownership for the artefact's creation to the user exclusively. Third, jugaad innovation similarly draws attention to innovation in resource-limited environments, but from a corporate and economic point of view. Therefore, the authors see the need to establish a new term that differentiates the concept at hand to enable a precise scientific discourse going forward.

\subsection{Conclusion}

We proposed a concept that focuses on the user's own creation of artefacts and that shifts the hermeneutic workload from the user's to the designer's side. Therefore, it is less dependent on the user's interpretation of the prototype and we assume that this can lead to a method that is less prone to wrong assumptions based on filtered information. At the same time, the designer is not affecting or implying a certain direction for the solution during the artefact's formation, which in turn limits the designer's immanent bias on the process. The designer's first interpretation of the problem to solve does not lead the process; instead, it rather follows the user's initial take on the problem.

We defined the key differences in comparison to existing approaches that are commonly used in the field of product development. To ensure the validity of our concept, we followed suggestions for theoretical structural validity from Pedersen et al. (2000, p. 6), based our effort on scientific triangulation and solely relied on the well-known and often cited theories of hermeneutics and media richness. Since the publication of these foundational works, there has been no known falsification through scientific discourse. Our paper proposes a novel approach to user integration via the means of artefacts at a theoretical level as a very early step. Additional investigation is necessary - and will follow - in order to leverage the theoretical approach into practical knowledge. Nevertheless, we want to present our current work to the scientific community for a fruitful debate. 


\subsection{Next steps}

In order to proceed with the concept of the UD-MFP, we need to leverage the theoretical concept to a usable method in practice for science and industry. As pointed out in section 4.3, there are three different touchpoints we need to investigate further and explore how we can use them to integrate the concept into the actual design process. The goal is to harness the UD-MFP as a source of information and validation. On the qualitative side of the pending research, there are additional interviews and contextual inquiries with users, who already build corresponding UD-MFP (e.g. in maker spaces). With an increased number of case studies, we can identify the factors and elements of the UD-MFP in the field, analyse their intent from the user's perspective, and facilitate the transformation of derived requirements into the design space from the designer's point of view. Based on this we will be able to design workshops with users and designers in order to explore the integration of the proposal into the product development process and quantify its impact. Additionally, we need to discover possible limitations and identify means to address them. Finally yet importantly, the influence of the Rosenthal and Hawthorne, effect, which we briefly touched on, may provide further insightful research questions.

\section{Acknowledgement}

This joint research effort between the Universidad Técnica Federico Santa Maria and the University of the Bundeswehr Munich would not have been possible without the support of the CONICYT FONDECYT No.1171037 project.

\section{References}

Bhatti, Y.A. and Ventresca, M. (2013), “How Can 'Frugal Innovation’ Be Conceptualized?”, SSRN Electronic Journal. https://doi.org/10.2139/ssrn.2203552

Boer, L. (2011), "Participatory Provocation?", Proceedings of the Participatory Innovation Conference 2011, Søndvnerborg, Denmark, pp. 18-23.

Boer, L. and Donovan, J. (2012), "Provotypes for participatory innovation", DIS '12: Proceedings of the Designing Interactive Systems Conference, ACM Press, Newcastle Upon Tyne, UK, pp. 388-397. https://doi.org/10.1145/2317956.2318014

Brown, T. (2009), Change by Design: How Design Thinking Transforms Organizations and Inspires Innovation, Harper Collins.

Buxton, B. (2007), Sketching User Experiences: Getting the Design Right and the Right Design, Morgan Kaufmann Publishers.

Camburn, B. et al. (2017), "Design prototyping methods: state of the art in strategies, techniques, and guidelines", Design Science, Vol. 3, p. e13. https://doi.org/10.1017/dsj.2017.10

Cappelli, P. et al. (2010), "Leadership Lessons from India”, Harvard Business Review, Vol. 88 No. 3, pp. $90-97$.

Daft, R.L. and Lengel, R.H. (1983), Information Richness. A New Approach to Managerial Behavior and Organization Design, Defense Technical Information Center, Fort Belvoir, VA. https://doi.org/10.21236/ ADA128980

Duc, A.N. and Abrahamsson, P. (2016), "Minimum Viable Product or Multiple Facet Product? The Role of MVP in Software Startups", In: Sharp, H. and Hall, T. (Eds.), Agile Processes, in Software Engineering, and Extreme Programming, Springer International Publishing, Cham, pp. 118-130.

Duraiswamy, V. et al. (2018). "Development of a Methodology for Robust Evaluation of Perceived Quality of Vehicle Body Panel Gaps", presented at the 15th International Design Conference, DESIGN, pp. 237-248. https://doi.org/10.21278/idc.2018.0432

Eckert, C., Maier, A. and McMahon, M. (2005), "Communication in design”, In: Clarkson, J. and Eckert, C. (Eds.), Design Process Improvement, Springer-Verlag, London, pp. 232-261.

Elverum, C.W., Welo, T. and Tronvoll, S. (2016), "Prototyping in New Product Development: Strategy Considerations", Procedia CIRP, Vol. 50, pp. 117-122. https://doi.org/10.1016/j.procir.2016.05.010

Gaver, B., Dunne, T. and Pacenti, E. (1999), “Design: Cultural probes”, Interactions, Vol. 6 No. 1, pp. 21-29. https://doi.org/10.1145/291224.291235

Gaver, W.W. et al. (2004), "Cultural probes and the value of uncertainty”, Interactions, Vol. 11 No. 5 , pp. 53. https://doi.org/10.1145/1015530.1015555

Gulati, R. (2010), "Management Lessons From the Edge”, Academy of Management Perspectives, Vol. 24 No. 2 , pp. 25-27.

Hansen, F. (1974), Konstruktionswissenschaft: Grundlagen Und Methoden, 1st ed., VEB Verlag Technik, Berlin. 
Heck, J. et al. (2016), "Iteration-based Performance Measurement in the Fuzzy Front End of PDPs", Procedia CIRP, Vol. 50, pp. 14-19. https://doi.org/10.1016/j.procir.2016.04.183

Houde, S. and Hill, C. (1997), "What do Prototypes Prototype?", Handbook of Human-Computer Interaction, 2nd ed., Elsevier, pp. 367-381. https://doi.org/10.1016/B978-0-444-81862-1.X5065-1

Jahnke, M. (2012), "Revisiting Design as a Hermeneutic Practice: An Investigation of Paul Ricoeur's Critical Hermeneutics", Design Issues, Vol. 28 No. 2, pp. 30-40. https://doi.org/10.1162/DESI_a_00141

Lauff, C., Kotys-Schwartz, D. and Rentschler, M. (2018), "What is a Prototype? What are the Roles of Prototypes in Companies?", Journal of Mechanical Design, Vol. 140, https://doi.org/10.1115/1.4039340.

Lim, Y.-K., Stolterman, E. and Tenenberg, J. (2008), "The anatomy of prototypes: Prototypes as filters, prototypes as manifestations of design ideas", ACM Transactions on Computer-Human Interaction, Vol. 15 No. 2, pp. 1-27. https://doi.org/10.1145/1375761.1375762

Liou, F.W. (2007), Rapid Prototyping and Engineering Applications: A Toolbox for Prototype Development, CRC Press, Taylor \& Francis, Boca Raton, FL.

Møller, L. and Tollestrup, C. (2013), Creating Shared Understanding in Product Development Teams, Springer London, London. https://doi.org/10.1007/978-1-4471-4180-8

Moogk, D.R. (2012), "Minimum Viable Product and the Importance of Experimentation in Technology Startups", Technology Innovation Management Review, pp. 23-26. https://doi.org/10.22215/timreview/535

Ojeda, L. and Pino, A. (2019), "Valparaíso y su comercio callejero: ¿Espacialidad esporádica y/o espacialidad saturada?", AUS, No. 25, pp. 11-19. https://doi.org/10.4206/aus.2019.n25-03

Pedersen, K. et al. (2000), "The 'Validation Square' - Validating Design Methods \& Research", presented at the ASME Design Theory and Methodology Conference, Baltimore, Maryland.

Punkka, T. (2012), "Agile Hardware and Co-Design", presented at the Embedded Systems Conference 2012, ESC-3008, Boston.

Radjou, N. et al. (2012), Jugaad Innovation: Think Frugal, Be Flexible, Generate Breakthrough Growth, Wiley.

Ricœur, P. (1972), "Der Text als Modell: hermeneutisches Verstehen", In: Bühl, W.L. (Ed.), Verstehende Soziologie: Grundzüge und Entwicklungstendenzen. Elf Aufsätze, Nymphenburger Verlagshandlung, München, pp. 252-283.

Ries, E. (2011), The Lean Startup: How Today's Entrepreneurs Use Continuous Innovation to Create Radically Successful Businesses, Crown/Archetype.

Rosenthal, R. and Fode, K.L. (1963), "The effect of experimenter bias on the performance of the albino rat", Behavioral Science, Vol. 8 No. 3, pp. 183-189. https://doi.org/10.1002/bs.3830080302

Sanders, E.B.-N. and Stappers, P.J. (2008), "Co-creation and the new landscapes of design", CoDesign, Vol. 4 No. 1, pp. 5-18. https://doi.org/10.1080/15710880701875068

Sanders, E.B.-N. and Stappers, P.J. (2014), "Probes, toolkits and prototypes: three approaches to making in codesigning", CoDesign, Vol. 10 No. 1, pp. 5-14. https://doi.org/10.1080/15710882.2014.888183

Savoia, A. (2011), Pretotype It, Second Pretotype Edition.

Schmidt, T.S. (2019), Towards a Method for Agile Development in Mechatronics: A Lead User-Based Analysis on How to Cope with the Constraints of Physicality, Shaker, Düren.

Schmidt, T.S. et al. (2017), "Media richness theory in agile development choosing appropriate kinds of prototypes to obtain reliable feedback", presented at the 2017 International Conference on Engineering, Technology and Innovation (ICE/ITMC), IEEE, Funchal, pp. 521-530. https://doi.org/10.1109/ICE.2017.8279930

Stappers, J.P. (2013), "Prototypes as a Central Vein for Knowledge Development", in Valentine, L. (Ed.), Prototype: Design and Craft in the 21st Century, Bloomsbury Publishing Plc, pp. 85-98. https://doi.org/ 10.5040/9781350036031

Stevanović, M., Marjanović, D. and Storga, M. (2016), "Managing the process of preparation for product development: Ideas assessment and evaluation", presented at the 14th International Design Conference, DESIGN 2016, Cavtat, Dubrovnik, Croatia, 16-19 May 2016, Faculty of Mechanical Engineering and Naval Architecture, pp. 1155-1164.

Ulrich, K.T. and Eppinger, S.D. (2012), Product Design and Development, McGraw-Hill/Irwin, New York.

Visser, F.S. et al. (2005), "Contextmapping: experiences from practice", CoDesign, Vol. 1 No. 2, pp. 119-149. https://doi.org/10.1080/15710880500135987

Zink, L. et al. (2017). "The use of prototypes within agile product development explorative case study of a Makeathon", presented at the 2017 International Conference on Engineering, Technology and Innovation (ICE/ITMC), IEEE, Funchal, pp. 68-77. https://doi.org/10.1109/ICE.2017.8279871. 